\title{
Drug interaction with coumarin derivative anticoagulants
}

\author{
STANDING ADVISORY COMMITTEE FOR HAEMATOLOGY OF THE ROYAL COLLEGE \\ OF PATHOLOGISTS
}

The use of oral anticoagulants in the form of coumarin derivatives in the treatment of thrombosis continues to carry the risk of inducing abnormal bleeding.

While the laboratory control of such treatment has been improved considerably by the introduction of standardisation (ICSH) ${ }^{1}$ and the use of British comparative reagents (ACP broadsheet), ${ }^{2}$ the increasing number of drugs that interact with these anticoagulant agents has enhanced the number of such often life-threatening events. ${ }^{3-10}$

These drugs may potentiate or antagonise the coumarin activity by affecting the binding of the anticoagulant drugs to plasma proteins or by affecting microsomal enzymes in the liver. This potentiating or inhibiting interaction varies with the drug used and there is also variation from patient to patient.

It is not the purpose of this communication to describe each interaction in detail but to draw the attention of all doctors to the increasing number of drugs that can influence this form of treatment. Further, the introduction of new drugs in preliminary clinical trials in man, before the granting of licence, can also produce unexpected effects.

Drugs and physical states that potentiate the response may require a reduction of the dose of oral anticoagulants or, conversely, the dose may have to be increased to maintain an effective anticoagulant effect once the drug is withdrawn.

Those drugs that inhibit the effect of anticoagulant drugs may make effective treatment impossible. If it is possible to maintain an effective low level of the $\mathrm{K}$ dependent factors (II, III, X) by giving a large dose the withdrawal of the inhibiting drugs may result in a precipitate fall of the II, VII, and X levels with consequent danger of spontaneous bleeding. The concomitant use of a definitely potentiating or antagonising drug along with oral anticoagulants should be avoided, but if the clinical state necessitates the risk then frequent laboratory surveillance is essential. When drugs with a less definite effect are used, careful control is also required until a "steady state" is established.

It is not the purpose of this paper to recommend the dose of oral anticoagulant drugs or to didactically lay down suitable laboratory methods for control of the "effective" and "safe" levels of anticoagulant treatment in any given patient. It has, however, been recommended that the one-stage prothrombin time be prolonged by a ratio of $2 \cdot 0-4.0$ of the normal control time (BCR), the degree of prolongation depending on the clinical condition of the patient. ${ }^{11}{ }^{12}$ When a potentiating drug is administered with an oral anticoagulant, the dose of coumarin should be reduced by about a third and the prothrombin time/ BCR checked in two to three days' time. Weekly testing may

Members of the committee were: F Stratton (Manchester), D G Chalmers (Cambridge), P T Flute (London), S M Lewis (London), J MacIver (Manchester), M G Nelson (Belfast), N K Shinton (Coventry), J Stuart (Birmingham), and H T Swan (Sheffield).

be necessary to attain dosage stability. Similar control testing will be required after withdrawal of an antagonising drug and also with change in the clinical stage of the patient.

\section{Drugs expected to potentiate oral anticoagulants}

Alcohol-dose dependent

Allopurinol (Zyloric)

Anabolic steroids

Aspirin and its analogues-in large doses

Azapropazone (Rheumox)

Chloramphenicol

Clofibrate (Atromid S)

Chlorpromazine (Largactil)

Cimetidine (Tagamet)

Co-trimoxazole (Bactrim, Septrin)

Danazol (Danol)

Dextrothyroxine

Disulfiram (Antabuse)

Ethacrynic acid (Edecrin)

Feprazone (Methrazone)

\section{Drugs which may potentiate oral anticoagulants}

Amiodarone

Aminoglycosides:

Gentamycin

Streptomycin

Tobramycin

Amikacin

Aminosalyclic acid

Ampicillin

Cephaloridine (Ceporin)

Chloral hydrate and related compounds

Chlorpropamide

Chlortetracycline

Cycloserine

Cyclophosphamide (Endoxana)

Diazoxide (Eudemine)

Dichloralphenazone (Welldorm)

Diflunisal (Dolobid)

Fenclofenac (Flenac)

Fenoprofen calcium (Fenopron, Progesic)

Flufenamic acid (Meralen)

Glucagon

Ketoprofen (Alrheumat) Mefenamic acid (Ponstan) Metronidazole (Flagyl)

Naproxen (Naprosyn, Synflex)

Neomycin

Oxymetholone (Anapolen)

Oxyphenbutazone (Tanderil)

Phenylbutazone (Butazolidin)

Phenyramidol (Analexin)-not available in the United Kingdom Quinidine

Salicylates (see aspirin)

Thyroxine

Triclofos sodium

Drugs which antagonise or may antagonise anticoagulant therapy

Antacids

Antihistamine

Barbiturates

Carbamazepine (Tegretol)

Cholestyramine (Questran)

Colestipol (Colestid)

Corticosteroids

Dichloralphenazone

Glutethimide (Doriden)
Ketoprofen (Orudis)

Liquid Paraffin

Methotrexate

Methylphenidate (Ritalin)

Mono-amine oxidase inhibitors

Paracetamol-high doses for several weeks (in dextropropoxyphene (Distalgesic))

Penicillin-in large doses intravenously

Phenformin (Dibotin)

Propylthiouracil

Quinine salts

Streptotriad

Sulindac (Clinoril)

Sulphonamides-long acting

Tetracyclines

Tolbutamide

Tricyclic antidepressants

Mercaptopurine

Oral contraceptives

Pheneturide

Phenytoin (Epanutin)

Primidone (Mysoline)

Rifampicin

Vitamin $K$-only $K_{1}$ and $K_{2}$
Indomethacin (Indocid)

Nalidixic acid (Negram) 


\section{Drugs potentiated by oral anticoagulants}

Chlorpropamide

Phenytoin

Tolbutamide

\section{Drugs which do not affect anticoagulant therapy}

Several commonly used drugs or group of drugs are known to have no proved effect. These are listed here as they may provide a practical alternative to an interacting drug.

\section{Adrenaline}

Ascorbic acid

Cardiac glycosides

Chlordiazepoxide (Librium)

Dextromoramide (Palfium)

Diazepam (Valium)

Flurazepam (Dalmane)

Ibuprofen (Brufen)

\author{
Levorphanol (Dromoran) \\ Methadone (Physeptone) \\ Morphine \\ Nitrazepam (Mogadon) \\ Pentazocine (Fortral) \\ Pethidine \\ Quinidine \\ Sulphonamides-short acting
}

Analgesics used for headache and minor trauma containing dextropropoxyphene or paracetamol, or both (Distalgesic), are safe for occasional self-medication in doses of 2-4 tablets daily once or twice a week, but regular ingestion of 6-8 tablets daily for chronic pain may require reduction of oral anticoagulant dosage.

While most interacting drugs operate by potentiating or antagonising the action of coumarin-like drugs, others, drugs such as aspirin, sulphinpyrazone, dipyridamole, and nonsteroidal anti-inflammatory drugs, act by impairing platelet function and so enhance the risk of bleeding especially in the gastrointestinal tract. Thus anticoagulant control alone will not reflect the potential risk of bleeding.

The patient's physical and clinical condition also complicates the use of anticoagulants. Any severe illness will increase sensitivity to oral anticoagulants and indicate reduction in dosage. Advancing age has the same effect and consequences. Pregnancy, on the other hand, has a pronounced inhibitory effect, and the use of anticoagulants in the early months of pregnancy is contraindicated because of possible teratological effects on the fetus.

The following have a proved potentiating effect:
Alcoholism

Cardiac failure

Cholestasis

Diarrhoea (enteritis)

Fever

Gastrocolic fistula

Hypoalbuminaemia

Liver damage (including exposure to organic solvents-for instance, petrol and possibly halothane in general anaesthesia)

Malnutrition

Renal impairment

Thyrotoxicosis

The committee wish to thank Drs A A Sharp and N K Shinton for compiling this report and Professor E A Loeliger of the Academich Zeidenhuis, Leiden, and Dr R Mibashan of King's College Hospital for their advice and criticisms.

\section{References}

${ }^{1}$ Ingram GIC, Hills $M$. Reference method for the one-stage prothrombin time test on human blood. International committee for standardisation in haematology. Thromb Haemostas 1976;36:237-8.

2 Poller L. The British comparative thromboplastin: the use of the national thromboplastin reagent for uniformity of laboratory control of oral anticoagulants and expression of results. Association of Clinical Pathologists Broadsheet 1970:71.

${ }^{3}$ Koch-Weser J, Sellars EW. Drug interaction with coumarin anticoagulants. $N$ Engl f Med $1971 ; 285: 487,547$.

4 Loeliger EA. Myler's side effects of drugs 8. Amsterdam, Oxford: Excerpta Medica, 1977:773.

${ }^{5}$ Loeliger EA. In: Dukes MNG, ed. Side effects of drug annual. Vol 1. Amsterdam, Oxford: Excerpta Medica, 1977:262.

6 Wade A, ed. Martindale. The extra pharmacopoeia. 27th ed. London: Pharmaceutical Press, 1977.

7 MIMS. London: Haymarket Publications Ltd, 1979.

${ }^{8}$ O'Reilly RA. Pharmacodynamics of the oral anticoagulant drugs. In: Spaet TH, ed. Progress in haemostasis and thrombosis. Vol 2. New York: Grune and Stratton, 1974:175.

${ }^{9}$ Hansten PD. Drug interactions. 4th ed. Philadelphia: Lea and Febiger, 1979.

10 Griffin JP, D'Arcy PF. A manual of adverse drug interactions. Bristol: John Wright and Sons Ltd, 1979.

11 Blackburn EK. Long-term anticoagulant therapy. Prescriber's fournal $1977 ; 16: 73$.

12 Loeliger EA. The optimal therapeutic range in oral anticoagulants. History and proposal. Thromb Haemostas 1979;42:114.

(Accepted 30 April 1982)
Is it safe to prescribe enteric-coated corticosteroid tablets for asthmatic patients?

The reason for giving enteric-coated prednisolone to patients with asthma is the same as when treating other conditions- to diminish the chances of gastric irritation and ulceration. I know of no published evidence to show that enteric-coated prednisolone has major disadvantages in the treatment of asthma. Enteric-coating of prednisolone does result in delayed absorption and slightly diminished peak concentrations compared with ordinary prednisolone, but the area under the concentration time and thus on the graph, the bioavailability of prednisolone, is the same after the two preparations. Thus for maintenance treatment there is unlikely to be any harm in giving enteric-coated prednisolone and some advantage in that it may reduce the incidence of gastrointestinal upset. Certainly for the treatment of the severe acute attack there may be disadvantages due to the delayed absorption and the enteric-coated tablets might be crushed, but it would seem more logical in the circumstances to provide the non-coated standard preparation.-JOHN Collins, consultant physician, London.

What is the most suitable form of house heating for infants and adults with asthma or bronchitis?

There is a notable lack of published work to support a categorical answer. Beyond the conventional wisdom that adequate, uniform temperature and humidity levels throughout the house are ideal, there is no convincing evidence that any one form of heating is physio- logically preferable to any other. Pragmatism would support a choice of whatever is most convenient and acceptable, and least costly. The safety of the system is more important than its type-for example, the hazard of carbon monoxide from faulty systems has been shown ${ }^{1}$ and, in a fascinating study of black children in a poor area of Baltimore, higher carbon monoxide levels indoors than in the busy streets outside were attributed to stoves and hot water heaters. ${ }^{2}$ Not only is it difficult to separate the type and quality of heating from other aspects of housing, but even community physicians, who have had extensive experience of dealing with applications for rehousing on health grounds, recognise that the multiple factors make it difficult to express an opinion about the relation between any particular physical illness and housing conditions. ${ }^{3}$ Nor can the matter rest there. A comparative study of rates of respiratory illness in children in three different areas in South Wales showed that the highest rate was to be found in a new council estate with district central heating and the lowest rate in the old traditional valley housing with open coal fires. The lung function test results were consistent, being best in the children from the traditional valley housing and worst in the new centrally heated estates. ${ }^{*}$ Unsurprisingly, this apparently bizarre reversal of expectation could not easily be explained, but it does appear to show that the factor of personal selection of the population concerned is crucial.A W MACARA, consultant senior lecturer in community medicine, Bristol.

\footnotetext{
World Health Organisation. Health hazards of the human environment. Geneva:

WHO, 1972 .
Spivey GH, Radford EP. Inner city housing and respiratory disease in children: a pilot study. Arch Environ Health 1979;34:23-30.

3 Muir Gray JA. Housing, health, and illness. Br Med f 1978;iii:100-1.

Yarnell JW, St Leger AS. Housing conditions, respiratory illness and lung function in children in South Wales. Br $\mathcal{F}$ Prev Soc Med 1977;31:183-8.
} 